\title{
The Syntagmatics of Noun Collocations in English
}

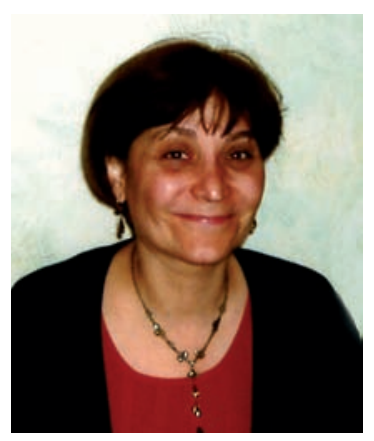

Gayane Muradyan

Tuman beings store not just words in isolation in their brains, but also the prototypical syntagmatic patterns associated with each word. Each syntagmatic pattern is associated with the potential of a word or phrase to contribute in a given context to the meaningfulness of an actual utterance. From a cognitive point of view, the idiosyncratic set of prototypes associated with each word, may be slightly different in the same speech community, but such is the normative power of social pressures that any gross differences in prototyping are in due time eliminated and stereotypes of word usage emerge.

The linguistic theories of the past have proved utterly inadequate as a foundation for a satisfactory lexicographical account of words, phrases, word partnerships, multi-word chunks and their semantic values, and only the development of very large corpora and the study of concordances of words in a large corpus providing evidence for how words are actually used in different syntagmatic units, made it possible to identify patterns of linguistic behaviour associated with each word. Therefore, what a large corpus enables us to discover and learn, is a stereotypical set of syntagmatic prototypes.

The target word of a syntagmatic unit (collocation, word-combination, word partnership) can be identified only through considering different groups of its normal uses according to its common syntagmatic features. A large corpus provides evidence of the patterns of usage with which meanings are associated. The larger the corpus, the more strikingly the patterns stand out. Syntagmatic linguistic behaviour (the semantic value of the words) tends to recur as a norm, so it is quite reasonable that the association of meanings with patterns will have considerable predictive power for interpreting the meaning of words.

Such norms for nouns are constructed quite differently from norms for verbs and other parts of speech. Noun norms focus on significant collocates, mainly making statements about prototypical usage. The function of the whole unit is thus conditioned rather by the collocate than by the target word. Studying the nature of the target noun nature, we have observed that most significant collocates in syntagmatic units with it are in a standard syntactic relation with the target word, e.g. course, return, dog, gases, study, human, worship, cure, good are statistically significant collocates of nature, and usually occur in the phrases course of nature, return to nature, dog nature, nature of gases, nature study, human nature, nature worship, nature cure, good nature. The nature can be violent, severe, tough, fearful, terrible, disastrous, rough. The man can be deceitful, kind, fierce, savage, sympathetic, unselfish, willing, thoughtful, cruel, strong, proud, ambitious, furious, unflinching by nature.

It must be mentioned that there are other collocates that are not in any fixed 
syntactic relation to nature, but are freely associated with words or word-combinations of four different semantic groups qualifying the nature of the noun nature:

universe, weather, rain, forest, animals, plants, trees, insects, disasters, torrents, floods, oceans, lakes, rivers, forces controlling the world;

outdoor, animal-like and uncivilized existence, primitive and simple life;

characteristics of a person or thing (mental or spiritual), qualities of non-material things (eg art, knowledge, language);

sort, kind

Together, all such statements are in no way random and add up to the cognitive profile of the noun nature which is normally organized and used on the basis of the relations between the target word and its significant collocates.

The adjective or other pattern collocates in the noun syntagms are generally prototypical. To activate the correct interpretation of the target word, it is necessary first to distinguish between those classifying collocates that identify the target word. In the case of nature it should be initially distinguished whether nature is considered as a natural phenomenon, a quality, etc and this can be done only through the collocate. The frequency of the set of classifying adjectives and noun modifiers that activate the sense of noun syntagms is very large indeed, virtually unbounded. Suffice it to bring some more examples in addition to those mentioned above with the noun nature:

social nature

political nature

financial nature

religious nature

rigid nature

avaricious nature

mean nature

dishonest nature

quiet nature

unargumentative nature

ferocious nature

courageous nature

unfathomable nature

sly nature

unique nature

In all the above cases the syntagmatic relationship between the target word and the collocate is quite clear. Whether the syntagm carries literal (social nature) or figurative meaning (unfathomable nature) is mostly identified as such by the collocate. In fact, not only the meaning of the collocation but also each of the metaphorical or nonmetaphorical uses can be identified by a particular collocate. In a few cases it is helpful or even necessary to import knowledge from outside the immediate context to make a correct interpretation. The wider context confirms the meanings to the point of certainty.

The most literal uses of nature involve nature curing or selecting. In other cases, 
the word nature itself may be used in a literal sense, but the associated verb is more metaphorical, i.e. the fact that the noun nature is being used in a metaphorical sense is signalled by the related verb. Typical of this second class are the expressions in which nature awakens, forces and demands. The degree of metaphoricity descends when nature ravages places or rages or when the human beings struggle with nature. These clichйs are so common that it is easy to overlook the metaphorical status of the verb. However, there is another case when the literal direct object in the form of nature follows a literal causative verb, and the apparent mixing results in a proper metaphoric verbal syntagm, namely to unleash nature. Such metaphorization has proved no obstacle to this collocation being conventionalized as a normal expression in English.

Thus, it is very important to mention that to a great extent it is the syntagmatic criteria that makes it possible to distinguish the metaphorical uses from the literal ones.

It should also be noted that many of the phrases with nature may be taken not as a chunk used in a metaphorical way but also as a chunk, formed on the basis of idiomaticity proper of the word-combination:

Pay the debt of nature.

$B e$ in a state of nature.

Become a second nature.

Answer lobey a call of nature.

The prototypical syntagmatics of all the four idiomatic uses of the word nature indicates that the last four collocations containing the word nature are evident enough to be comprehended as idioms proper but not easily guessed through the meanings of the target word and the collocates though. Semantically they express more than the sum of their parts, i.e. their meanings cannot be derived from the analysis of the literal meanings of the words of which they are composed. The Longman's Dictionary of English Idioms (1999) and the NTC's Thematic Dictionary of American Idioms (2001) define the idiom to pay the debt of nature as "to die", to be in a state of nature as a euphemistic expression of "naked", "with no clothes on", to become a second nature as an acquired trait of a person's natural character and to answer/obey a call of nature as a humourous expression of "the need to go to the lavatory".

However, further textual clues can add to the determination of the meaning of both literal and figurative syntagmatic noun units without preliminary knowledge of them. The semantic parameters are set by the text type, i.e. the most important clue in such cases is the domain or discourse type in which the text belongs: fiction, science, news, arts, etc. The meaning of the syntagm in a text or discourse becomes more and more functional as the writing (called "document" by Patrick Hanks) proceeds. As we have already noted, more information from the wider context is required to enable the reader to know what's going on. In such cases, pragmatic knowledge about the domain is often important: one has to know not only what kind of paper one is reading but also what normally happens in that kind of writing.

Generalizations made on the study of syntagmatic patterns with the word nature, demonstrate clearly enough the significant syntagmatic characteristics of the English noun collocations. 
The syntagmatics of noun collocations is a norm, in each noun syntagm a special norm based on a stereotypical syntagmatic prototype has become established and to this extent all the collocations are like single words: each is associated with a set of prototypical patterns of usage.

Another noteworthy feature of the syntagmatic criteria is that the significant collocate conditions the nature of the whole syntagmatic pattern to a great extent.The prototypical syntagmatic criteria for idiomaticity, metaphoricity and non-metaphoricity is identified through distinguishing the meanings by the syntagmatic relationship of the collocations.

The task of identifying and producing meaningful utterences can be carried out effectively by systematic classification of observed uses of collocations as norms in a procedure called corpus pattern analysis.

At large, the syntagmatic set of various prototypes or the major syntagmatic patterns contribute to the norm for general English.

The functional stylistic motivation or the discourse type is to a great extent signalled by the syntagmatic linguistic behaviour of collocations.

\section{References:}

1. Alexandrova O.V., Ter-Minasova S.G. English Syntax (Collocation, Colligation and Discourse). Moscow, 1987.

2. Fillmore Charles J. Framenet and the Linking between Semantic and Syntactic Relations. Geneva, 2003.

3. Hanks Patrick. The Syntagmatics of Metaphor and Idiom. Berlin: Brandeis University and Berlin-Brandenburg Academy of Sciences, 2004.

4. Kilgarriff Adam, Tugwell David. Word Sketch: Extraction and Display of Significant Collocations for Lexicography. France, Toulouse: ACL, 2001.

5. Lewis M. The Lexical Approach. Prague, Hove: Language Teaching Publications, 1993.

6. Taylor John R. Linguistic Categorization: Prototypes in Linguistic Theory. Oxford University Press, 1995.

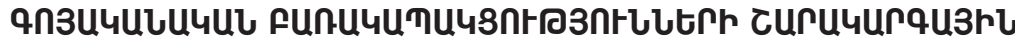

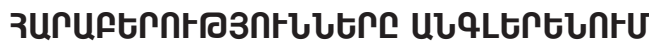

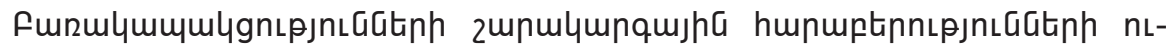

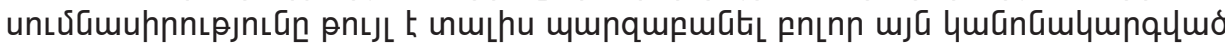

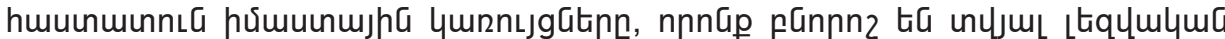

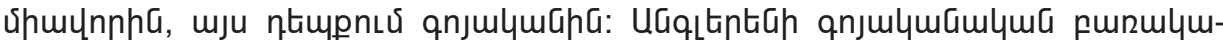

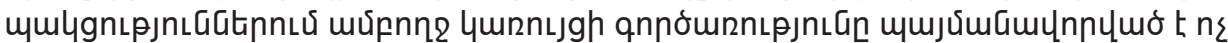

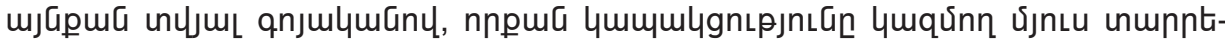

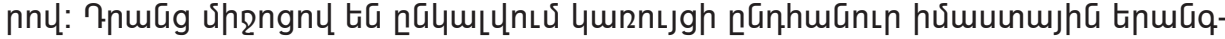

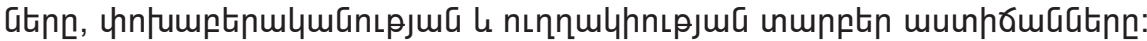

